\title{
Diaspidid (Hemiptera: Coccoidea) size plasticity as an adaptive life history trait
}

\author{
M. GarRy HILL ${ }^{1}$, Rosa C. HENDERSON ${ }^{2}$ and Nicola A. MAUCHLINE ${ }^{1}$ \\ ${ }^{1}$ The New Zealand Institute for Plant \& Food Research Limited, Te Puke Research Centre, 412 No .1 Rd, Te Puke 3182, \\ New Zealand; e-mail: Garry.Hill@plantandfood.co.nz \\ ${ }^{2}$ Landcare Research Ltd, Private Bag 92170, Auckland Mail Centre, Auckland 1142, New Zealand
}

Key words. Life history, developmental biology, Diaspididae, fecundity, host plant resistance, polyphagy, plasticity

\begin{abstract}
The size and fecundity of Hemiberlesia lataniae (Signoret) (Hemiptera: Diaspididae) on partially resistant and susceptible kiwifruit (Actinidia spp.) varieties was measured. The size ratio of mature H. lataniae grown on a partially resistant genotype, compared with those on a susceptible genotype, was $0.67-0.51$ for $2^{\text {nd }}$ instar exuviae area, 0.32 for adult body area and 0.18 for estimated body volume. The fertility ratio was 0.1 , but the pre-oviposition period and the size of the crawlers were the same. Diaspidid scale insects' unusual ability to continue growing after the final moult appears to be a key feature allowing these insects to show extreme size plasticity while retaining the ability to reproduce even when very small. These observations challenge current theories of insect development that postulate the need to achieve a critical weight threshold before the final moult. We suggest that this strategy may have assisted the evolution of polyphagy within the Diaspididae.
\end{abstract}

\section{INTRODUCTION}

Armoured scale insects (Hemiptera: Diaspididae) boast a number of unusual and in some cases unique characteristics (Miller \& Kosztarab, 1979, Kosztarab, 1987; Gullan \& Kosztarab, 1997). Amongst these are a hard, waxy protective covering or scale (Foldi, 1990b), neoteny (Koteja, 1990), high levels of polyphagy (Beardsley \& Gonzales, 1975; McClure, 1990c) and high rates of speciation (Miller \& Davidson, 2005; Provencher et al., 2005). Another unusual feature, which has been largely ignored, is the ability of the adult female to grow substantially after the final moult. In his review of diaspidid life history strategies, Koteja (1990) noted this unusual trait but pointed to a dearth of detailed observations on it. That the female continues to growth after the final (second) moult is apparent to anyone studying diaspidids, as the second instar exuviae becomes incorporated into the scale cover and in most species continues to be visible as the size of the scale cover expands with the growth of the insect beneath (Foldi, 1990a). In a detailed study of the growth of Hemiberlesia rapax (Comstock) on potato, Blank et al. (2000) noted that while 552 degree-days were required to complete the final (second) moult, an additional 440 degree-days were required on average before the insects began to lay eggs, during which time the insects increased substantially in size.

The size plasticity in the adult stage of diaspidids has escaped the attention of those studying insect growth and maturation, with a recent review stating that adult insects do not grow (Nijhout, 2003). Indeed, this condition of achieving major changes in body shape and size after the final moult appears to be quite unusual amongst insects.

The size plasticity of armoured scale insects was brought to our attention during studies of the growth of a parthenogenetic strain of Hemiberlesia lataniae (Signo- ret) on kiwifruit [Actinidia chinensis Planch. and A. deliciosa (A. Chev.) C.F. Laing \& A.R. Fergusson], in which we were investigating host-plant resistance. Bark of the variety $A$. deliciosa "Hayward" is susceptible to $H$. lataniae, whereas the bark of $A$. chinensis "Hort16A" is completely resistant (Hill et al., 2007, 2009). A third variety, A. chinensis "Hort22D", showed partial resistance, supporting the growth of $H$. lataniae but resulting in adult insects that were estimated to be one-fifth of the size of mature $H$. lataniae grown on A. deliciosa "Hayward" (Hill et al., 2010). In spite of their small size, the $H$. lataniae adults grown on A. chinensis "Hort22D" were perfectly formed, produced mature embryos and laid eggs that hatched into healthy crawlers. However, the number of embryos inside the insects reared on A. chinensis "Hort22D" at the onset of reproduction (average 3.5) was about $10 \%$ of that for insects reared on the susceptible $A$. deliciosa "Hayward" (average 34). This ability may allow $H$. lataniae and possibly other diaspidid species to survive and reproduce on host-plants that are nutritionally very poor. Here we investigate the biology of $H$. lataniae developing on susceptible and partially resistant Actinidia genotypes and discuss the potential implications for the evolution of polyphagy within the Diaspididae.

\section{MATERIAL AND METHODS}

\section{Estimating scale insect size on kiwifruit cultivars}

Six-month-old dormant kiwifruit canes were harvested from A. deliciosa "Hayward" and A. chinensis "Hort22D" vines on 24 July 2007 , wrapped in polythene, and stored at $0^{\circ} \mathrm{C}$. On 19 September 2007 the canes were removed from cold storage and forty-centimetre lengths were cut from 10 canes of each variety and prepared for bioassay (Hill et al., 2010). Buds were cut from the cane sections and grafting wax applied to all exposed tissue with the exception of the bottom end of the cane, which was placed into a plastic cup containing water. Wool yarn was 
wound loosely around the cane to provide a protected settling site for the crawlers.

The canes were kept in a constant environment room at $21^{\circ} \mathrm{C}$ and $70 \% \mathrm{RH}$ with a natural light regime at the Te Puke Research Centre, New Zealand. On 19 September 2007, $60 \mathrm{H}$. lataniae crawlers from a laboratory-maintained culture reared on squash and potatoes, were seeded individually onto each cane using a small paint brush.

Twelve weeks after crawler seeding (on 18 December 2007), a Nikon Coolpix 995 camera was used to individually photograph $10 \mathrm{H}$. lataniae females from each cane, using a calibrated frame that allowed the area of the insect to be accurately measured (Hill et al., 2005). The photographs were taken using methods described by Hill et al. (2005). The image of one scale cover from each cane was chosen at random and its total area, and that of the second instar exuviae, were measured using the image processing software, ImageJ (version $1.37 \mathrm{v}$; http://rbs.info.nih.gov/ij/) (Hill et al., 2005). Adult females at the onset of reproduction (12 weeks after hatching) from each treatment were slide-mounted in water and the number of mature eggs ("embryos") within the body of the female scale insect (an indicator of fecundity) was counted at $50 \times$ magnification, using a compound microscope. The number of specimens examined were 26 from "Hayward" and 28 from "Hort22D".

The remaining adult females from each of the two treatments were killed and fixed in $70 \%$ alcohol, cleared, stained and slidemounted. Detailed measurements of the body and pygidium were made using a compound microscope and calibrated graticule, as follows (Fig. 1):

1. Body length of adult female: from the anterior margin of the head to the posterior end of median lobes (i.e., including lobes). Measured at $100 \times$ magnification (Fig. 1, vertical solid line)

2. Body width of adult female: measured transversely at the level of the posterior spiracles, which is close to the widest part of the insect's body. Measured at 100× magnification (Fig. 1, horizontal solid line).

3. Body length of crawler: same measurements as for adults, except measured on $400 \times$ magnification.

4. Antenna length of crawler: the maximum length from the pedicel to the apical point, choosing the straightest antenna; $400 \times$ magnification.

5. Pygidium length of adult female, method 1: on the ventral surface, in a line from the anterior median margin of the sclerotised pygidial area to the posterior margin of the body between the median lobes (not including the lobes), using the paired setal bases located more dorsally, between and near the base of the lobes, as a defined end marker. Measured at $400 \times$ magnification (Fig. 1, vertical dotted line).

6. Pygidium width of adult female, method 1: focusing on the dorsal surface and the paired lateral pre-anal scars, measured the maximum width from the lateral margin of one pre-anal scar to the lateral margin of the other, using $400 \times$ magnification (Fig. 1, horizontal dotted line)

7. Pygidium length of adult female, method 2: focusing on the dorsal surface, measured in a line from the anterior margin of median pre-anal scar to the posterior margin of the body between the median lobes (not including the lobes), using $400 \times$ magnification. This included the paired setal bases situated more dorsally, between and near the base of the lobes, as a defined end marker (as in 5 above) (Fig. 1, vertical dashed line).

8. Pygidium width of adult female, method 2: focusing on the ventral surface, the distance between the near-parallel sclerotised bars associated with the perivulvar pores, in particular the short sclerotised region between the anterior and posterior

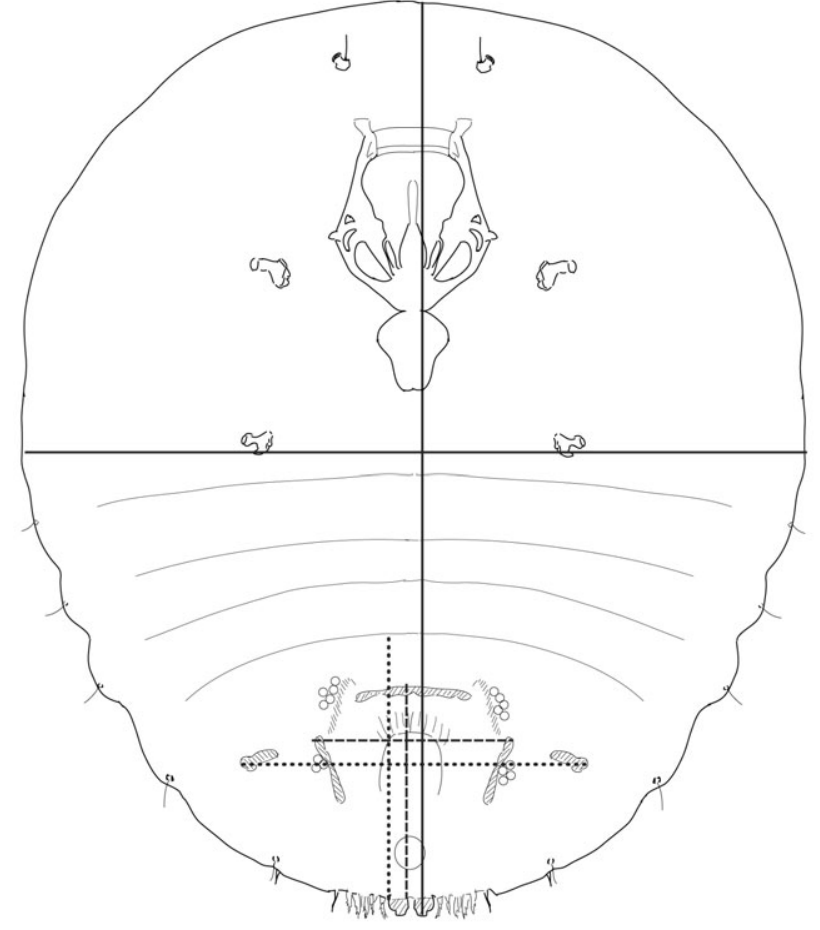

Fig. 1. Drawing of a cleared and slide-mounted adult female Hemiberlesia lataniae showing the measurements taken to characterise overall body size (solid lines) and pygidium dimensions (method 1 - dotted lines; method 2 - dashed lines). See text for details.

perivulvar pore groups on each side, using $400 \times$ magnification (Fig. 1, horizontal dashed line).

9. A count of the total number of perivulvar pores present on each adult female.

The volume of $25 \mathrm{H}$. lataniae adults growing on each kiwifruit variety was estimated approximately from the slidemounted adult insect dimensions (measurements 1 and 2 above), and further assuming that the insects were conical in shape with an elliptical base, with the dorsal and ventral surfaces meeting at an angle of $30^{\circ}$. Based on these assumptions, the formula for the volume becomes: Volume $=\mathrm{v}\left(\right.$ Basal area/p)*Tan $(30)^{*}$ Basal area/3.

This experiment was repeated on 18 December 2009, with $H$. lataniae settled onto A. deliciosa "Hayward" and A. chinensis "Hort22D" canes. Photographs of the resultant $H$. lataniae adults were taken on 25 February 2010, when the insects were 10 weeks old. Measurements of exuviae and scale areas were made and embryo numbers were counted. The onset of reproduction (crawler production) and fertility (numbers of crawlers produced) was determined using the methods of Hill et al. (2009). Each of the remaining adult females was surrounded by a clear sticky tape band ("all weather tape") with a hole punched through it to accommodate the insect. Crawlers released by the insect were trapped on the sticky band. The bands were changed twice a week, and a record was kept of the number of crawlers trapped each time.

\section{RESULTS}

Hemiberlesia lataniae is ovoviviparous, laying eggs containing fully developed embryos that hatch into scale crawlers beneath the parent's scale cover a short time (0-2 days) after being laid. H. lataniae insects developing 
TABLE 1. Comparison of adult female Hemiberlesia lataniae body dimensions (mean \pm SE) (see Fig. 1) and the number of perivulvar pores for insects reared at $21^{\circ} \mathrm{C}$ and $70 \% \mathrm{RH}$ on canes of the partially resistant experimental kiwifruit genotype Actinidia chinensis "Hort22D" and the susceptible genotype A. deliciosa "Hayward"; n = 35. All measurements recorded on 12-week-old $H$. lataniae adults in 2007.

\begin{tabular}{|c|c|c|c|c|c|}
\hline & $\begin{array}{l}\text { Actinidia deliciosa } \\
\text { "Hayward" (susceptible) }\end{array}$ & $\begin{array}{l}\text { Actinidia chinensis "Hort22D" } \\
\text { (partially resistant) }\end{array}$ & $t$ & $P$ & $\begin{array}{c}\text { Size ratio: } \\
\text { A. chinensis / A. deliciosa }\end{array}$ \\
\hline Body length (mm) & $1.30 \pm 0.018$ & $0.74 \pm 0.018$ & 21.9 & $<0.001$ & 0.57 \\
\hline Body width (mm) & $1.05 \pm 0.01$ & $0.59 \pm 0.012$ & 24.9 & $<0.001$ & 0.56 \\
\hline Pygidium length 1 (mm) & $0.28 \pm 0.002$ & $0.21 \pm 0.004$ & 15.3 & $<0.001$ & 0.77 \\
\hline Pygidium width $1(\mathrm{~mm})$ & $0.31 \pm 0.001$ & $0.24 \pm 0.003$ & 21.0 & $<0.001$ & 0.77 \\
\hline Pygidium length $2(\mathrm{~mm})$ & $0.22 \pm 0.001$ & $0.17 \pm 0.003$ & 14.1 & $<0.001$ & 0.77 \\
\hline Pygidium width 2 (mm) & $0.16 \pm 0.001$ & $0.13 \pm 0.003$ & 8.2 & $<0.001$ & 0.81 \\
\hline No. perivulvular pores & $29.7 \pm 0.63$ & $18.7 \pm 0.72$ & 11.3 & $<0.001$ & 0.63 \\
\hline
\end{tabular}

on the partially resistant variety A. chinensis "Hort22D" were substantially smaller than those developing on the susceptible variety $A$. deliciosa "Hayward". From the detailed body measurements taken in 2007, the ratio of $H$. lataniae adult body length and width on the partially resistant "Hort22D" compared with the susceptible "Hayward" variety was $0.56-0.57$ (Table 1 ). The ratio of perivulvar pore numbers was 0.63 (Table 1 ). The ratio of pygidium dimensions ranged between 0.83 and 0.77 (Table 1).

In 2007 and 2010, the ratio of $H$. lataniae second instar exuvial area between $A$. chinensis "Hort22D" and A. deliciosa "Hayward" was 0.51 and 0.67 , while the ratios of adult scale cover area were 0.25 and 0.19 respectively (Table 2). The ratio of $H$. lataniae insect body area estimated from slide mounts between $A$. chinensis "Hort22D" and $A$. deliciosa "Hayward" was 0.32 , which translated into an estimated body volume ratio of 0.18 (Table 2).

The fecundity ratio (embryo number) between $A$. chinensis "Hort22D" and A. deliciosa "Hayward" was $0.1-0.07$, while the fertility ratio (comparing numbers of crawlers produced) up to 110 days after initial parental scale settlement between $A$. chinensis "Hort22D" and $A$. deliciosa "Hayward" was 0.04 (Table 3). In spite of these marked differences in size and fecundity, there was no difference in the pre-oviposition period (about 80 days) nor crawler size between $H$. lataniae growing on $A$. chinensis "Hort22D" and A. deliciosa "Hayward" (Table 3).

\section{DISCUSSION}

\section{Relative changes in $\boldsymbol{H}$. lataniae body dimensions on partially resistant and susceptible kiwifruit varieties}

The timing of the second (final) moult was not recorded, but the size of the exuviae showed that $H$. lataniae moulted at a much smaller size on A. chinensis "Hort22D" than on A. deliciosa "Hayward". The quite large differences in the relative sizes of the $2^{\text {nd }}$ instar exuviae between insects reared on A. chinensis "Hort22D" and A. deliciosa "Hayward" in the two experiments (2007 compared with 2010) (33\% and 49\%) were caused by variation in the exuviae size on $A$. chinensis "Hort22D" canes (Table 2), possibly reflecting a difference in the food quality of $A$. chinensis "Hort22D" canes, although the influence of differences in scale culture material cannot be ruled out. The difference in final scale cover area (cover area on "Hort22D" was $19-25 \%$ of the size on "Hayward") and estimated insect body area (body area on "Hort22D" was $32 \%$ of the size on "Hayward") compared with the exuviae size differences showed that the differential $H$. lataniae growth rates between the two kiwifruit varieties were maintained into adulthood, leading to an estimated body volume difference of $82 \%$ (estimated body volume on "Hort22D" was $18 \%$ of the size on "Hayward") between adult females on the two hosts. Presumably, the smaller reduction in the pygidial dimensions (estimated pygidial linear measurements on "Hort22D" were $77-83 \%$ of the size on "Hayward") than in overall body size reflected the increased sclerotization in that region and possibly the need to maintain a minimum vulva size to allow for the exit of full-sized

TABLE 2. Comparison of Hemiberlesia lataniae second instar exuviae area, adult scale cover area, insect body area and body volume (mean \pm SE) at the onset of reproduction in $2007(12$ weeks old, $n=10)$ and $2010(10$ weeks old, $n=30)$ for insects developing on canes of susceptible (Actinidia deliciosa "Hayward") and partially resistant (A. chinensis "Hort22D") kiwifruit at $21^{\circ} \mathrm{C}$ and $70 \% \mathrm{RH}$.

\begin{tabular}{|c|c|c|c|c|c|c|}
\hline & Date & $\begin{array}{l}\text { Actinidia deliciosa } \\
\text { "Hayward" } \\
\text { (susceptible) }\end{array}$ & $\begin{array}{l}\text { Actinidia chinensis } \\
\text { "Hort22D" } \\
\text { (partially resistant) }\end{array}$ & $t$ & $P$ & $\begin{array}{l}\text { Size ratio: } \\
\text { A. chinensis / } \\
\text { A. deliciosa }\end{array}$ \\
\hline \multirow{2}{*}{ Second instar exuviae area $\left(\mathrm{mm}^{2}\right)$} & 2007 & $0.466 \pm 0.025$ & $0.239 \pm 0.027$ & 6.7 & $<0.001$ & 0.51 \\
\hline & 2010 & $0.462 \pm 0.014$ & $0.309 \pm 0.011$ & 8.43 & $<0.001$ & 0.67 \\
\hline \multirow{2}{*}{ Adult scale area $\left(\mathrm{mm}^{2}\right)$} & 2007 & $1.603 \pm 0.114$ & $0.415 \pm 0.034$ & 10.6 & $<0.001$ & 0.25 \\
\hline & 2010 & $1.852 \pm 0.123$ & $0.345 \pm 0.023$ & 12.1 & $<0.001$ & 0.19 \\
\hline Estimated area of body $\left(\mathrm{mm}^{2}\right)$ & 2007 & $1.081 \pm 0.031$ & $0.346 \pm 0.016$ & 22.0 & $<0.001$ & 0.32 \\
\hline Estimated volume $\left(\mathrm{mm}^{3}\right)$ & 2007 & $0.123 \pm 0.005$ & $0.0227 \pm 0.001$ & 19.8 & $<0.001$ & 0.18 \\
\hline
\end{tabular}


TABLE 3. Comparison of number of embryos per adult female Hemiberlesia lataniae at the onset of reproduction, number of eggs laid up to 110 days after initial insect settlement, the pre-oviposition period and crawler size for insects reared at $21^{\circ} \mathrm{C}$ and $70 \% \mathrm{RH}$ on canes of the partially resistant kiwifruit genotype Actinidia chinensis "Hort22D" and the susceptible genotype A. deliciosa "Hayward". $\mathrm{N}=35$, except for pre-oviposition period and eggs laid ("Hort22D" $\mathrm{n}=18$; "Hayward" $\mathrm{n}=44$ ) and crawler dimensions ( $\mathrm{n}=$ 25-30). All measurements were recorded on 12-week-old H. lataniae adults in 2007, with the exception of number of eggs laid and pre-oviposition period, which were taken from 10-week-old adults in 2010. Embryo numbers were recorded in both 2007 and 2010.

\begin{tabular}{|c|c|c|c|c|c|}
\hline & $\begin{array}{c}\text { Actinidia deliciosa } \\
\text { "Hayward" (suscep-tible) }\end{array}$ & $\begin{array}{l}\text { Actinidia chinensis "Hort } \\
\text { 22D" (partially resistant) }\end{array}$ & $t$ & $P$ & $\begin{array}{c}\text { Size ratio: } \\
\text { A. chinensis / A. deliciosa }\end{array}$ \\
\hline \multirow[t]{2}{*}{ Embryo number } & $33.8 \pm 1.1$ & $3.5 \pm 1.4$ & 11.2 & $<0.001$ & 0.10 \\
\hline & $47.2 \pm 2.0$ & $3.4 \pm 0.24$ & 10.7 & $<0.001$ & 0.07 \\
\hline No. eggs laid to 110 days & $90.4 \pm 6.6$ & $3.4 \pm 0.69$ & 13.0 & $<0.001$ & 0.04 \\
\hline Pre-oviposition period (d) & $80.1 \pm 0.5$ & $81.6 \pm 2.3$ & 0.85 & 0.41 & 1.00 \\
\hline Crawler body length $(\mu \mathrm{m})$ & 242 & 238 & 0.94 & 0.35 & 1.00 \\
\hline Crawler antenna length $(\mu \mathrm{m})$ & 60.2 & 59.5 & 0.61 & 0.55 & 1.00 \\
\hline
\end{tabular}

eggs. The ability to have such marked adult size plasticity may have arisen following the development of the protective scale, which has allowed the insects to reduce cuticular sclerotisation. Lack of sclerotisation and an undifferentiated, neotenous morphology presumably allows the female armoured scale to continue growing after the final moult.

The measures of fecundity and fertility show even larger differences between the two hosts, of over $90 \%$, no doubt reflecting the problem that the small adults growing on $A$. chinensis "Hort22D" face in producing crawlers of a fixed size from a body that is less than one-fifth the size of females on $A$. deliciosa "Hayward". Possibly the most interesting observations from this study are that adult $H$. lataniae reared on A. chinensis "Hort22D", in spite of their severely reduced size, can produce viable crawlers that behave normally by dispersing from under the female scale, and that they do so without any pre-oviposition time penalty compared to the much larger adults growing on A. deliciosa "Hayward" canes.

The crawler production data for $H$. lataniae females on A. chinensis "Hort22D" are an underestimate of their total fertility. The experiment was stopped after 110 days because of the death of the $A$. chinensis "Hort22D" canes, which did not last as long in water as $A$. deliciosa "Hayward" canes. The fertility of $H$. lataniae on "Hort22D" canes would have been greater had the canes survived for longer. However, the relative difference in $H$. lataniae performance between $A$. chinensis "Hort22D" and A. deliciosa "Hayward" would probably have been retained. In a prior field experiment investigating life table parameters of armoured scale insects, we measured the fertility of $H$. lataniae on canes of susceptible and partially resistant experimental genotypes of $A$. chinensis (Hill et al., 2009). The $H$. lataniae pre-oviposition and oviposition periods were the same on both susceptible and partially-resistant genotypes (Fig. 2) (Hill et al., 2009), but on the partially resistant genotype, $H$. lataniae adults produced $78 \%$ fewer crawlers per female than on the susceptible genotype (19 cf. 89). Neither adult body nor scale cover sizes were recorded in that study.

In the only comparable study of diaspidid size and fecundity on resistant and susceptible host plants, Mizuta $(2003,2004,2005)$ found that the estimated fecundity of the biparental diaspidid Pseudaulacaspis pentagona Targioni-Tozzetti (white peach scale) reared on the resistant tea cultivars, "Sayamakaori" and "Hatsumomiji" was 5 to $10 \%$ of that on the susceptible cultivar, "Takachiho", while the pre-oviposition period was $6-12 \%$ longer on the resistant genotypes. The total adult female body length on the most resistant tea genotypes was $68 \%$ that of an adult grown on a susceptible tea genotype. These figures are very similar to those observed for $H$. lataniae, suggesting that the same adaptations to variations in host plant quality may operate for parthenogenetic and biparental diaspidid species. Mizuta's study is unique in having measured male size and development time on resistant and susceptible tea hosts. He found that the size differential of males was very similar to that of females and the developmental times also varied by the same amount (0.88-0.92) (Mizuta 2004, 2005). Thus the developmental time synchronisation of the sexes, which is believed to be important in biparental populations for ensuring successful mating (Gullan \& Kosztarab, 1997), was maintained when feeding on resistant tea varieties (Mizuta 2004). Hare et al. (1990) observed that Aonidiella aurantii Maskell (citrus red scale) settling on the bark of lemon or grapefruit survived better and grew larger than those settling on orange bark, while mandarin bark was not suitable for $A$. aurantii settlement or survival. Several other studies have noted variation in scale insect size on different host plants, and associated changes in fecundity (Garcia, 1973; McClure, 1990a).

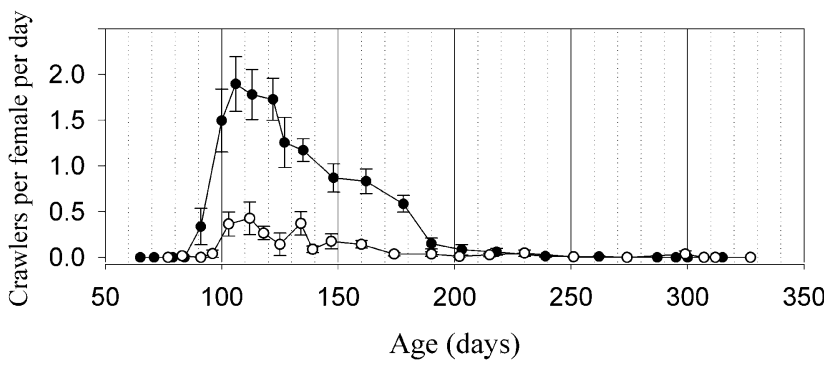

Fig. 2. Lifetime fecundity profile (crawlers per female per day \pm SE) for Hemiberlesia lataniae on susceptible (black circles) and partially resistant (open circles) Actinidia chinensis experimental genotypes. Modified from Hill et al. (2009). 


\section{Diaspidid adult size plasticity as an adaptation to variable host plant nutritional status}

While variation in body size and fecundity in relation to diet has been commonly observed in other insect orders (Awmack \& Leather, 2002; Nijhout, 2003), body size and fecundity/fertility differences of $80-90 \%$ would appear to be unusual. This study suggests that there is a developmental and reproductive strategy that allows $H$. lataniae to adapt to feeding on hosts of widely varying nutritional status. Development times (pre-oviposition and oviposition periods) appear to be more or less fixed. Body size varies greatly dependent upon the suitability of the host plant. Crawler size (and by inference, egg size) is fixed, and fertility is therefore correlated with overall body size, which is directly related to host plant nutritional status. This strategy will provide diaspidid females with the best chance of reproducing on a nutritionally poor host, and may have facilitated the evolution of extreme polyphagy, as observed in many diaspidids including $H$. lataniae (McClure, 1990c; Miller \& Davidson, 2005). The ability of diaspidid populations to adapt locally to individual host plants and form demes (McClure, 1983; Hanks \& Denno, 1994; van Zandt \& Mopper, 1998; Alstad, 2002), or cryptic species (Miller \& Kosztarab, 1979; Provencher et al., 2005) may also be facilitated by this ability to mature and lay limited numbers of offspring on poorquality host plants. It should also be noted that diaspididae are renowned for their morphological plasticity, dependent upon feeding site. Some species have markedly different morphology depending upon whether they are growing on the leaves or bark of a particular host (Takagi, 1990).

\section{Diaspidid populations attaining a small size on sub-optimal host plants will minimise the impact of parasitism}

By growing on a sub-optimal host plant and attaining a reduced size, a diaspidid may reduce the risk of attack from co-evolved specific parasitoids. Koinobiont parasitoids [i.e. all endoparasitoids and a wide range of ectoparasitoids that require the host to continue growing to a minimum size after oviposition before commencing their development (Jervis \& Kidd, 1996)], are unlikely to be able to complete development in these extremely small hosts. Furthermore, some idiobiont parasitoids of diaspidids (which prevent host growth after oviposition) preferentially seek out larger hosts for oviposition. For example, aphelinid parasitoids preferentially parasitise large A. aurantii (Hare et al., 1990; Morgan \& Hare, 1997; Karaca, 1998). Thus, the selective disadvantage to diaspidids growing on sub-optimal host plants may be partially and significantly offset by reductions in mortality caused by natural enemies.

\section{Is extremely small size the normal body size in diaspidids?}

Does the small $H$. lataniae body size observed on $A$. chinensis "Hort22D" represent the "normal" condition, and the large $H$. lataniae body size observed on $A$. deliciosa "Hayward" result from $H$. lataniae feeding on a cultivated plant with super-abundant food supplies compared with a host growing in a natural forest? McClure (1980, 1990b) demonstrated that the fertilisation of host trees and subsequent increased foliar nitrogen increased Fiorinia externa Ferris survival by up to $40 \%$ and increased its fecundity by up to $100 \%$ when developing on needles of a range of conifer species. In this situation, we speculate that diaspidid size plasticity after the final moult would have allowed the insects to take advantage of the increased nutrients in the plant to continue growing, thereby increasing their fecundity. The relative importance of size plasticity in either (a) allowing the insect to benefit from favourable host plant nutrition by continuing growth, or (b) allowing it to survive plant defence responses by maturing and reproducing while still very small, will require more observations of a range of species growing in natural and modified habitats and under a range of nutrient regimes. In addition it should be noted that other factors such as rearing temperature will affect diaspidid body size at maturation for example, high rearing temperatures produce smaller A. aurantii (Yu \& Luck, 1988).

\section{Physiological explanations for body size variation}

Studies of insect growth and associated physiological changes have in most instances found an observable relationship, either positive or negative, between body size and age at maturity (Nijhout, 2003; Stern, 2003; Berner \& Blanckenhorn, 2007). The widely accepted physiological model of insect growth posits that size in insects is determined by the attainment of a size threshold in the final instar, the critical weight (or size), at which an irreversible endocrine cascade is triggered, characterised by a decline in juvenile hormone titres and an increase in ecdysteroid hormone levels, culminating in the initiation of metamorphosis (Nijhout, 2003). In the interval during which these changes are occurring in the final larval or nymphal instar, the insect continues to feed and grow and may almost double in size (Berner \& Blanckenhorn, 2007). This model has been successful in explaining the relationship between size and age over a range of environmental and genetic factors (but not host plant quality, as far as we are aware) for a number of arthropod and vertebrate species, leading to a general conclusion that most multicellular organisms must acquire a specific amount of resources, manifested as size or weight thresholds, before they can enter reproductive life (Berner \& Blanckenhorn, 2007). The results presented here challenge that assertion. Many of the detailed invertebrate physiological studies have been carried out on reduviid bugs, model laboratory Diptera (Drosophila) and Lepidoptera (Manduca) (Nijhout, 1984, 2003; Stern, 2003), but to our knowledge physiological growth studies have not been carried out on neotenous insects. The results presented here show not only an extreme range in adult body size but also a lack of correlation between maturation time and body size in $H$. lataniae. The general observation that diaspidid species grow several-fold after the final moult - i.e. in the adult stage - would suggest that a different physiological process is operating to determine 
final body size in these insects, or that if the insect does have a critical weight determining maturation, it is triggered after the final moult.

Whatever physiological mechanisms are involved, the adaptive nature of $H$. lataniae's growth and reproductive strategies to cope with low food quality is evident. $H$. lataniae does not test the substrate for palatability before settlement (Hill \& Holmes, 2009) and therefore first instars are unaware of the suitability of their chosen host plant/site until after they have become sessile. Thus, a strategy aiding survival on unsuitable or marginal host plants, by being able to reproduce when very small (albeit with a substantial reduction in fecundity) is a major advantage for diaspidids.

\section{CONCLUSIONS}

Size plasticity in the adult female diaspidid allows the insect to grow substantially after the final moult. Final adult female size in $H$. lataniae can vary by more than five-fold, depending on the suitability of the host plant. Fecundity varies with body size, but the time to the onset of reproduction and the quality of the crawlers are not substantially affected. We hypothesize that this strategy is an adaptation to variable host plant quality that facilitates the evolution of polyphagy and arises as a result of the insect's neoteny, scale formation, reduced cuticular sclerotisation, and an ability to continue growth after the final moult. These observations disagree with the generally accepted theory of size determination in insects, based upon the concept of "critical size" determination in the last pre-adult instar. Further research is needed to determine how widespread this phenomenon is amongst the Diaspididae and to test the ability of diaspidid populations, both biparental and uniparental, to persist on and adapt to sub-optimal host plants.

ACKNOWLEDGEMENTS. We are grateful to B. Normark, G. Watson and anonymous referees for valuable comments on an earlier draft. The work was funded by the New Zealand Foundation for Research Science and Technology (C06X0301).

\section{REFERENCES}

Alstad D.N. 2002: Population structure and the conundrum of local adaptation. In Wagner M.R., Clancy K.M., Lieutier F. \& Paine T.D. (eds): Mechanisms and Deployment of Resistance in Trees to Insects. Kluwer, Dordrecht, pp. 3-21.

Awmack C. \& Leather S. 2002: Host plant quality and fecundity in herbivorous insects. Annu. Rev. Entomol. 47: 817-844.

Beardsley J.W. \& Gonzales R.H. 1975: The biology and ecology of armoured scales. Annu. Rev. Entomol. 20: 47-73.

BERNER D. \& BlANCKENHORN W.U. 2007: An ontogenetic perspective on the relationship between age and size at maturity. Funct. Ecol. 21: 505-512.

Blank R., Gill G.S. \& Kelly J.M. 2000: Development and mortality of greedy scale at constant temperatures. Environ. Entomol. 29: 934-942.

FoldI I. 1990a: Moulting and scale cover formation. In Rosen D. (ed.): Armoured Scale Insects, their Biology, Natural Enemies and Control. Vol. 4A. Elsevier, Amsterdam, pp. $257-265$.
Foldi I. 1990b: The scale cover. In Rosen D. (ed.): Armoured Scale Insects, their Biology, Natural Enemies and Control. Elsevier, Amsterdam, pp. 43-54.

GARCIA M.F. 1973: Contribution to the biological study of Parlatoria oleae (Colvee) (Homoptera, Coccoidea, Diaspidinae). Revta Invest. Agropec. (5, Pat. Veg.) 10: 1-53.

Gullan P.J. \& Kosztarab M. 1997: Adaptations in scale insects. Annu. Rev. Entomol. 42: 23-50.

Hanks L.M. \& Denno R.F. 1994: Local adaptation in the armored scale insect Pseudaulacaspis pentagona (Homoptera: Diaspididae). Ecology 75: 2301-2310.

HaRe J.D., Yu D.S. \& LuCK R.F. 1990: Variation in life history parameters of California red scale on different citrus cultivars. Ecology 71: 1451-1460.

Hill M.G. \& Holmes T. 2009: An analysis of latania scale (Hemiberlesia lataniae) settlement behaviour on kiwifruit leaves and bark. N. Z. Plant Prot. 62: 56-62.

Hill M.G., Mauchline N., Cate L.R. \& Connolly P.G. 2005: A technique for measuring the growth rate of armoured scale insects. N. Z. Plant Prot. 58: 288-293.

Hill M.G., Mauchline N., Cheng C.H. \& Connolly P.G. 2007: Measuring the resistance of Actinidia chinensis to armoured scale insects. Acta Hortic. 753: 685-692.

Hill M.G., Mauchline N.A., Hall A.J. \& Stannard K.A. 2009: Life table parameters for two armoured scale insect species on resistant and susceptible kiwifruit (Actinidia sp.) germplasm. N. Z. J. Crop Hortic. Sci. 37: 335-343.

Hill M.G., Mauchline N., Connolly P.G. \& Maher B. 2010: Measuring resistance to armoured scale insects in kiwifruit (Actinidia) germplasm. N. Z. J. Crop Hortic. Sci. 38: 69-85.

Jervis M.A. \& Kidd N. 1996: Insect Natural Enemies, Practical Approaches to their Study and Evaluation. Chapman and Hall, London, 491 pp.

KARACA I. 1998: Parasitization efficacy of Aphytis melinus DeBach (Hymenoptera: Aphelinidae) as affected by host size and size distribution of Aonidiella aurantii (Maskell) (Homoptera: Diaspididae) in a lemon orchard. Turkiye Entomol. Dergisi 22: 101-108.

Kosztarab M. 1987: Everything unique or unusual about scale insects (Homoptera: Coccoidae). Bull. Entomol. Soc. Am. 33: 215-220.

KотелA J. 1990: Life History. In Rosen D. (ed.): Armoured Scale Insects, their Biology, Natural Enemies and Control. Elsevier, Amsterdam, pp. 243-254.

MCCLURE M.S. 1980: Foliar nitrogen: A basis for host suitability for elongate hemlock scale, Fiorinia externa (Homoptera: Diaspididae). Ecology 61: 72-79.

MCCluRE M.S. 1983: Reproduction and adaptation of exotic hemlock scales (Homoptera: Diaspididae) on their new and native hosts. Environ. Entomol. 12: 1811-1815.

McClure M.S. 1990a: Habitats and hosts. In Rosen D. (ed.): Armoured Scale Insects, their Biology, Natural Enemies and Control. Elsevier, Amsterdam, pp. 285-288.

MCCLURE M.S. 1990b: Influence of environmental factors. In Rosen D. (ed.): Armoured Scale Insect, their Biology, Natural Enemies and Control. Elsevier, Amsterdam, pp. 319-330.

McClure M.S. 1990c: Patterns of host specificity. In Rosen D. (ed.): Armoured Scale Insects, their Biology, Natural Enemies and Control. Elsevier, Amsterdam, pp. 301-303.

Miller D.R. \& Davidson J.A. 2005: Armoured Scale Insect Pests of Trees and Shrubs. Cornell University Press, Ithaca, $442 \mathrm{pp}$.

Miller D.R. \& Kosztarab M. 1979: Recent advances in the study of scale insects. Annu. Rev. Entomol. 24: 1-27.

Mizuta T. 2003: Differences in development and reproduction of the mulberry scale, Pseudaulacaspis pentagona Targioni 
(Hemiptera: Diaspididae), on resistant and ssuceptible varieties of tea plant. Jap. J. Appl. Entomol. Zool. 47: 91-95.

Mizuta T. 2004: Mechanisms of Resistance of Tea to the Mulberry Scale Pseudaulacaspis pentagona. PhD. Thesis, Tea Branch, Miyazaki Prefecture Agricultural Experiment Station, $85 \mathrm{pp}$.

Mizuta T. 2005: Studies on the mechanism of Pseudaulacaspis pentagona (Targioni) (Hemiptera: Diaspididae) resistance of tea plant and its practical use. Bull. Miyazaki Agr. Exp. Stat. 40: $1-54$.

Morgan D.J.W. \& Hare J.D. 1997: Uncoupling physical and chemical cues: the independent roles of scale cover size and kairomone concentration on host selection by Aphytis melinus DeBach (Hymenoptera: Aphelinidae). J. Insect Behav. 10: 679-694.

Nishout H.F. 1984: Abdominal stretch reception in Dietalogaster maximus (Hemiptera: Reduviidae). J. Insect Physiol. 30: 629-633.

Nishout H.F. 2003: The control of body size in insects. Dev. Biol. 261: 1-9.
Provencher L.M., Morse G.E., Weeks A.R. \& Normark B.B. 2005: Parthenogenesis in the Aspidiotus nerii complex (Hemiptera: Diaspididae): a single origin of a worldwide, polyphagous lineage associated with Cardinium bacteria. Ann. Entomol. Soc. Am. 98: 629-635.

STERN D.L. 2003: Body size control: how an insect knows it has grown enough. Curr. Biol. 13: R267-269.

TAKaGi M. 1990: Polymorphism. In Rosen D. (ed.): Armoured Scale Insects, their Biology, Natural Enemies and Control. Elsevier, Amsterdam, pp. 59-64.

YU D.S. \& LUCK R.F. 1988: Temperature-dependent size and development of California red scale (Homoptera: Diaspididae) and its effect on host availability for the ectoparasitoid, Aphytis melinus DeBach (Hymenoptera: Aphelinidae). Environ. Entomol. 17: 154-161.

vAN ZANDT P.A. \& Mopper S. 1998: A meta-analysis of adaptive deme formation in phytophagous insect populations. Am. Nat. 152: 595-604.

Received July 15, 2010; revised and accepted October 4, 2010 